\title{
Pulse grazing by reindeer (Rangifer tarandus) increases the phylogenetic diversity of vascular plant communities in the Fennoscandian tundra
}

\author{
Kate Gibson $^{1}$, Johan Olofsson ${ }^{2}$, Arne Mooers $^{1}$, and Melanie Monroe ${ }^{1}$ \\ ${ }^{1}$ Simon Fraser University \\ ${ }^{2}$ Umea Universitet
}

October 14, 2020

\begin{abstract}
Herbivore grazing is an important determinant of plant community assemblages. We used data from a multi-year experimental study in Northern Fennoscandia to analyze the effect of reindeer (Rangifer tarandus) grazing on plant community diversity including its phylogenetic structure. Similar to previous studies on low productivity ecosystems in this region, we found no effect of grazing on plant biodiversity and a transition from dwarf shrubs to graminoids with pulse (i.e. grazed every other year) and press (i.e. grazed every year) grazing. Interestingly, communities with pulse grazing were more phylogenetically dispersed than communities with press grazing and lightly grazed communities. We argue that the indirect effects of reindeer grazing (e.g. interspecific competition and soil nutrient availability) may work in opposition of the direct effects (i.e. physical removal of species) and that the phylogenetic structure of the resulting community will depend upon the relative strengths of the direct and indirect effects. This interpretation suggests that the indirect effects of reindeer grazing in our study region are more important than the direct effects in driving community assembly for plant communities that are exposed to pulse grazing. Our results have important implications for the management of reindeer in Fennoscandia if pulses of grazing can increase the phylogenetic diversity of plant communities.
\end{abstract}

Pulse grazing by reindeer (Rangifer tarandus) increases the phylogenetic diversity of vascular plant communities in the Fennoscandian tundra

Kate Gibson $^{1}$, Johan Olofsson ${ }^{2}$, Arne $\varnothing$ Mooers $^{1}$, Melanie J Monroe ${ }^{1,2}$

${ }^{1}$ Department of Biology, Simon Fraser University, 8888 University Drive, Burnaby, British Columbia, V5A 1S6, Canada

${ }^{2}$ Department of Ecology and Environmental Science, Umeå University, Umeå, 901 87, Sweden

Author for correspondence: Kate Gibson, Department of Biology, Simon Fraser University, Burnaby, British Columbia, V5A 1S6, Canada; kfgibson@sfu.ca, ORCiD ID: 0000-0003-3970-6767

Johan Olofsson: johan.olofsson@umu.se, ORCiD ID: 0000-0002-6943-1218

Arne Mooers: amooers@sfu.ca

Melanie Monroe: monroemj.evolution@gmail.com, ORCiD ID: 0000-0003-1692-7938

Abstract

Herbivore grazing is an important determinant of plant community assemblages. We used data from a multi-year experimental study in Northern Fennoscandia to analyze the effect of reindeer (Rangifer tarandus 
) grazing on plant community diversity including its phylogenetic structure. Similar to previous studies on low productivity ecosystems in this region, we found no effect of grazing on plant biodiversity and a transition from dwarf shrubs to graminoids with pulse (i.e. grazed every other year) and press (i.e. grazed every year) grazing. Interestingly, communities with pulse grazing were more phylogenetically dispersed than communities with press grazing and lightly grazed communities. We argue that the indirect effects of reindeer grazing (e.g. interspecific competition and soil nutrient availability) may work in opposition of the direct effects (i.e. physical removal of species) and that the phylogenetic structure of the resulting community will depend upon the relative strengths of the direct and indirect effects. This interpretation suggests that the indirect effects of reindeer grazing in our study region are more important than the direct effects in driving community assembly for plant communities that are exposed to pulse grazing. Our results have important implications for the management of reindeer in Fennoscandia if pulses of grazing can increase the phylogenetic diversity of plant communities.

Keywords: biodiversity; community structure; grazing; herbivore; phylogenetic diversity

\section{Introduction}

Herbivory is an important factor influencing plant community assemblages directly through the physical removal of plant species (Lubchenco 1978), and indirectly by altering patterns of ecosystem productivity (McNaughton et al. 1988) and nutrient availability (Mazumder et al. 1988). As a result, herbivores may alter species composition (Augustine and McNaughton 1998), measures of richness (Olff and Ritchie 1998), and the phylogenetic structure (Cavender-Bares et al. 2009) of plant communities. Plant species richness and evenness (Tilman et al. 1997) and phylogenetic diversity (Faith 1992) are both important for ecosystem function and productivity (Liu et al. 2018). Thus, understanding the impact of reindeer grazing on plant communities is essential for directing conservation efforts in regions where reindeer are managed (Olofsson et al. 2004).

Herbivore activity can both increase and decrease the diversity of plant species (Olff and Ritchie 1998, Proulx and Mazumder 1998). According to the Intermediate Disturbance Hypothesis plant communities will increase or decrease their biodiversity as a function of the level of disturbance (Grime 1973, Connell 1978). Low disturbance levels (e.g., grazing) may increase plant species richness by removing dominant and competitive species, increasing light exposure to soil and increasing nutrient availability (Olff and Ritchie 1998, Proulx and Mazumder 1998, Bakker et al. 2003). High levels of disturbance/grazing, however, may decrease species richness due to insufficient recovery periods, trampling and erosion (Olff and Ritchie 1998). The nutrient availability of an ecosystem may play a role in determining the grazing intensity that results in the greatest biodiversity overall (Proulx and Mazumder 1998). If nutrient-rich ecosystems are more likely to have a few dominant species that respond quickly to disturbance (Rosenzweig 1971, Huston 1979), nutrientrich communities may experience peak levels of biodiversity at greater grazing intensities. Nutrient-poor ecosystems, however, which are common in the North, are limited by their regrowth ability and thus are expected to achieve the greatest species richness at lower grazing intensities (Proulx and Mazumder 1998, Sundqvist et al 2019). Thus, experimentally increased grazing is more likely to result in increased species richness in nutrient-rich ecosystems but have no effect or result in decreased diversity in nutrient-poor ecosystems.

Herbivores may also alter the phylogenetic structure of communities, though predictions are complex (Cavender-Bares et al. 2009). If anti-herbivore defense traits have a significant phylogenetic signal (Loiola et al. 2012, Yessoufou et al. 2013, but see Kursar et al. 2009), then generalist herbivores may act as a biological filter (Begley-Miller et al. 2014), resulting in a community that is more phylogenetically clumped i.e. communities including more closely-related species than drawn from the regional pool. However, if anti-herbivore defense traits are evolutionarily convergent, a generalist herbivore may increase the phylogenetic dispersion (communities including more distantly related species) of a community. In contrast, when multiple specialist herbivores are present and defense traits are highly conserved within plant clades, the community may become phylogenetically clumped. However, if defense traits are evolutionarily convergent then seemingly random patterns of species relatedness may result (Cavender-Bares et al. 2009). Alterna- 
tively, if herbivores both (1) decrease competition via removal of dominant plant species from a community and (2) increase nutrient availability via changes in nutrient cycling, herbivory may result in phylogenetic dispersion as intense competition between distantly related taxa (Mayfield and Levine 2010) and limited nutrient availability (Hurteau et al. 2016) both drive phylogenetic clumping.

The most extensive form of human land use in the northern Fennoscandian tundra is grazing by reindeer (Rangifer tarandus), and the major populations of reindeer across different regions have increased, decreased or remained stable over recent decades (Uboni et al. 2016). As the tundra is considered a low productivity environment with low nutrient availability, we expect low levels of reindeer grazing to have no effect or a negative effect on plant species diversity. The effects of reindeer grazing on tundra plant communities are significant (Suominen and Olofsson 2000, Austrheim and Eriksson 2001), as demonstrated by the pronounced replacement of dwarf shrubs by graminoids in grazed areas (Olofsson et al. 2001, Sundqvist et al 2019). However, the direction and size of the effect on other measures of biodiversity varies (Bernes et al. 2015, Sundqvist et al 2019): plant species richness generally increases with reindeer grazing in areas dominated by moss-like lichens, i.e. Cladonia species (Suominen and Olofsson 2000, Austrheim and Eriksson 2001), while communities lacking lichen mats experience no effects (Olofsson and Oksanen 2005), weak effects (Suominen and Olofsson 2000), or mixed effects that vary among regions (Olofsson et al. 2001). Additionally, a Scandinavia-wide study found that reindeer grazing decreased species richness in sites with low productivity, but increased species richness in productive sites (Sundqvist et al. 2019). Although many of the effects of reindeer grazing on biodiversity are well-studied, they are still not well-understood, and we have no data on the impact of reindeer grazing on phylogenetic community structure. Understanding the impact of reindeer on phylogenetic structure may provide insight into mechanisms driving community assembly (Webb et al. 2002 ) in this region and help inform good management practise.

Here we study the effects of reindeer grazing on plant community structure using data from a multi-year experiment including varying intensities of grazing: light (almost never grazed), acute i.e. pulse (grazed every other year), and chronic i.e. press (grazed every year), in the region of Raisduoddar in northern Norway. First, we analyzed the effect of grazing on the diversity of vascular plant species. Based on previous work in Fennoscandia, we predicted that in the nutrient-poor tundra, both pulse and press grazing would have no effect or negative effects on species richness and evenness. Second, we analyzed the effect of grazing on plant species composition with the prediction that the pulse and press grazed areas would be composed of different species from the lightly grazed areas, specifically with the replacement of dwarf shrubs by graminoids (Olofsson et al. 2001). Finally, we analyzed the effect of grazing on the phylogenetic structure of the vascular plant communities. As reindeer are generalist herbivores (Baskin and Danell 2003) and anti-herbivore traits are generally evolutionarily conserved (Loiola et al. 2012, Yessoufou et al. 2013, but see Kursar et al. 2009), we predicted that grazing would result in appreciable phylogenetic clustering such that species in areas with pulse and press grazing would be more closely related to one another than those in lightly grazed areas.

\section{Materials and Methods}

Study site

Our study was conducted in Raisduoddar, a sub-oceanic area in Troms fylke, northern Norway (69@30'N, 27@20'E) approximately 600-700m above sea level with pre-dominating Empetrum-Dicranum-Lichen vegetation (Oksanen and Virtanen 1995). In northern Norway, reindeer are managed and migrate from winter grazing areas in inner Finnmark to summer grazing areas near the coast (Suominen and Olofsson 2000). During the 1960's a permanent fence was constructed in Raisduoddar to prevent reindeer from entering migration areas or winter ranges during the summer. The fence is made from wire and wooden stakes approximately one meter above the ground and spans several kilometers over the tundra. While the side of the fence in the summer range is heavily grazed, the side in the spring and autumn ranges is only lightly grazed due to deep snow during the spring migration and the rapid movement of reindeer towards winter ranges in the autumn (Olofsson et al. 2001). Hereafter this fence will be referred to as the permanent fence. While the alpine regions in Scandinavia are generally considered to be low productivity, our study site has calcareous rock, which facilitates the growth of more plant species and thus increases the productivity of the 
region to intermediate (relative to the surrounding low productivity areas).

\section{Experimental design}

In 2004 five temporary fences were constructed along the permanent fence, extending approximately $6 \mathrm{~m}$ into the summer (heavily) grazed side of the fence, before reindeer entered the area in the autumn. Each of the temporary fences is between 85 and 185 meters in length and built in areas that allowed for the capturing of terrain and elevational differences. The temporary fences were taken down every other year to allow for grazing in the area closest to the permanent fence every second year (Figure 1a). The area on the inside of the temporary fence was thus exposed to acute (i.e. pulse grazing) after more than forty years of chronic (i.e. press grazing), while the areas outside of the temporary fence continued to experience press grazing. We placed permanent plots in the sites along the permanent fence where the temporary fences were constructed ( $\mathrm{n}=5$ sites). Each site contained two sets of triplets ( $\mathrm{n}=6$ plots) except for the fourth fence, which contained four sets of triplets $(\mathrm{n}=12$ plots), for a total of 36 permanent plots (Figure $1 \mathrm{~b}$ ). At each site, one set of triplets was placed in a drier area (18 plots in total) and the other in a moist/wet area (18 plots in total); we refer to this covariate as wet/dry. Within each triplet, each of the three plots was exposed to a different grazing intensity: the plot on the side of the permanent fence in the spring and autumn ranges was lightly grazed (12 plots in total), the plot inside the temporary fence was grazed every other year (pulse grazing; 12 plots in total), and the plot on the side of the permanent fence in the summer grazed area was grazed every year (press grazing; 12 plots in total). All plots were placed no more than $12 \mathrm{~m}$ from the permanent fence, but plots on the lightly grazed side of the fence were placed $3 \mathrm{~m}$ away from the fence due to the man-made disturbance in this area from herders walking next to the fence. Each plot was $3 \mathrm{~m} \times 3 \mathrm{~m}\left(9 \mathrm{~m}^{2}\right)$ and was evenly split into nine $1 \mathrm{~m} \times 1 \mathrm{~m}\left(1 \mathrm{~m}^{2}\right)$ sub-plots.

\section{Vegetation data collection}

We sampled the vascular plant vegetation from all the permanent plots in mid-late July (when most plants were flowering) for each of the years from 2004-2007. All plots were sampled every year, except for one plot in 2006 and three plots in 2007 due to inadvertent human disturbance, for a total of 140 plot-level samples. Sampling was done at the sub-plot level: the nine sub-plots of each permanent plot were fully sampled for species presence/absence data. Species were identified based onDen nya nordiska floran (Stenberg and Mossberg 2003); if an individual plant could not be identified based on what remained it was not recorded; some plants could only be identified to the genus level (e.g. Taraxacum sp.) and were recorded as such. In the centre sub-plot of each permanent plot we sampled relative species abundance based on plant cover. We used a $50 \mathrm{~cm} \times 50 \mathrm{~cm}$ transparent plexi-glass table with 100 randomly distributed $4 \mathrm{~mm}$-diameter holes: a pin of the same diameter was lowered through each hole and the number of contacts the pin had with each species was recorded (see also Olofsson et al. 2001).

\section{Diversity metrics}

\section{Species diversity}

We measured community richness using: (1) species richness (SR), (2) the Shannon-Wiener diversity index (H') (Shannon and Weaver 1949), and (3) Smith and Wilson's (1996) index of evenness (E $\mathrm{E}_{\mathrm{var}}$ ). Species presence/absence data was collected for all sub-plots, so to avoid pseudo-replication we calculated a single species richness measure for each plot by averaging the species richness of the nine sub-plots. In addition to calculating the overall species richness of each plot, we calculated the species richness of shrubs (25 species total), herbs (102 species total), and graminoids (52 species total) separately. Our other two measures of community richness required species abundance data, which was only collected for one sub-plot in each plot, so $\mathrm{H}^{\prime}$ and $\mathrm{E}_{\mathrm{var}}$ measurements at the plot-level were taken from a single sub-plot.

\section{Phylogenetic diversity}

\section{Phylogeny construction}

To study the effect of reindeer grazing on phylogenetic diversity, we constructed a regional vascular plant 
phylogeny. After reducing all taxonomy assignments to the species-level, which involved re-assigning subspecies, hybrids, and synonymous species, we identified 145 unique species from our samples to include in the regional phylogeny. DNA sequences for these species for the genes matK and rbcL were collected from GenBank (Supplementary material Appendix 1, Table A1). If sequence information was not available for one or both of matK and rbcL for a species, we used the closest-relative within the same genus with available matK and/or rbcL sequence information. Sequences for the identified species or close relative were available for 138/145 species for rbcL and 140/145 for matK (Supplementary material Appendix 1, Table A1). Two species did not have available sequence information for either gene and did not have a close relative that could be substituted:Cerastium cerastoides and Carex parallela. C. cerastoides was manually inserted at the base of the Cerastiumclade (Scheen et al. 2004) and C. parallela was manually inserted into a clade with Carex dioica (Lipnerová et al. 2013).

To ensure the correct reading frame prior to sequence alignment, all sequences were translated to amino acids in ExPASy (Gasteiger et al. 2003). Alignments were completed in MEGA7 (Kumar et al. 2016) using MUSCLE with the nucleotides for the coding regions of plant plastids and default settings. Non-informative gaps were manually removed from the matK alignments and excess lengths were trimmed from the ends of both genes. We identified GTR $+\mathrm{G}+\mathrm{I}$ as the best model for rbcL and GTR $+\mathrm{G}$ as the best model for matK using the Model Selection tool in MEGA7.

Bayesian inference of trees was performed using MrBayes (Huelsenbeck and Ronquist 2001) with two partitions: one for matK and one for rbcL. We ran our model for 100000000 generations with 4 chains at a temperature of 0.2 and a stop value of 0.01 for convergence. The sample frequency was set to every 1000 generations with a burn-in fraction of 0.25 and the trees were dated by constraining seven nodes (Table 1; Bell et al. 2010). The analysis converged at 10304000 generations. We illustrate the posterior with the majority rule consensus tree, created by collapsing clades with posterior probabilities less than $50 \%$ to polytomies (Supplementary material Appendix 1, Figure A1).

\section{Phylogenetic structure}

We used mean pairwise distance (MPD) as our measure of phylogenetic structure. MPD is more sensitive to changes in distantly related taxa than is the mean nearest taxon distance (Webb et al. 2002). To prevent bias resulting from calculations due to distantly related species (e.g.Lycopodium species), we used only the angiosperms (133/145 sampled species) to calculate MPD. We calculated a standardized measure of MPD with the aid of the function ses.mpd , in the R package "picante" by comparing the observed phylogenetic community structure to a specified null model with a randomized community structure (Kembel et al. 2010, R Core Team 2019). Using taxa that were identified to the species-level, we calculated both (1) a presence/absence-based measure of MPD (calculated at the sub-plot level and then averaged within each plot) and (2) an abundance-based measure (calculated for a single sub-plot in each plot), by weighting the pairwise distances by the product of the relative abundance of each species in each pair. Both MPD metrics were calculated for every tree in the posterior sample (created by merging the two runs and removing the $25 \%$ burn-in: final $n=15,458$ trees) and averaged to produce a single measure for each plot. For our null model we used the independentswap algorithm (with 1000 iterations per run and 999 runs), which randomizes the community data matrix while maintaining species occurrence frequency and sample species richness (Gotelli 2000). We used the p-value, or quantile, of observed MPD vs. the MPD of null communities as our standardized response variable, as this metric is less biased than the more common Net-Relatedness Index (Vamosi et al. 2014). Our measure describes the rank of the observed phylogenetic dispersion relative to the distribution produced by the null model. A value of 0 corresponds to a community that is more clumped than any of the null communities, a value of 0.5 corresponds to a community that has a median dispersion relative to the null communities, and a value of 1 corresponds to a community that is more dispersed than any of the null communities. We refer to these metrics as phylogenetic dispersion (from the species presence/absence data) and abundance-weighted phylogenetic dispersion (from the relative species abundance data).

Statistical analysis 


\section{Species \&3 phylogenetic diversity}

We analyzed the effect of grazing intensity on SR (overall and for the shrubs, herbs, and graminoids), H', $\mathrm{E}_{\mathrm{var}}$, phylogenetic dispersion and abundance-weighted phylogenetic dispersion using linear mixed effects models with site as a random effect (following Begley-Miller et al. 2014) and grazing, year, a grazing:year interaction, and wet/dry as fixed effects. First, we tested the grazing:year interaction using a likelihood ratio test. If the interaction was not significant $(\mathrm{p}>0.05)$, then we removed it from the model and tested the remaining fixed effects. If a significant effect of grazing or year was found $(\mathrm{p}<0.05)$, then a post-hoc analysis was performed with Tukey pair-wise comparisons. To control for the possibility that changes in phylogenetic dispersion may result from the transition of communities from dwarf shrubs to graminoids, we also tested the effect of grazing on phylogenetic dispersion and abundance-weighted phylogenetic dispersion with the same procedure described above, while controlling for the proportion of species that are graminoids (for phylogenetic dispersion) and the proportion of the relative abundance that are graminoids (for abundanceweighted phylogenetic dispersion). All analyses were performed in $\mathrm{R}$ version 3.6.0 ( $\mathrm{R}$ Core Team 2019).

\section{Community structure}

To compare the community structure of plots we used the Bray-Curtis dissimilarity index, calculated using vegdist from the R package "vegan" (Oksanen et al. 2016), as a measurement of the distance between plant communities based on our relative species abundance data. To partition variance within the distance matrix, we used a non-parametric permutational multivariate analysis of variance (PERMANOVA), as implemented in the vegan function adonis. Significance values and pseudo F-statistics were obtained from permutations (n $=1000$ ) restricted within each site due to our nested experimental design. Given that this technique allowed us to perform a multivariate analysis, we include grazing, year, a grazing:year interaction, and wet/dry as covariates. When significant values $(\mathrm{p}<0.05)$ were obtained, we performed a post-hoc analysis with Bonferroni corrections to correct for multiple comparisons in the PERMANOVA.

To visualize and corroborate the results of the PERMANOVA, we used a non-metric multi-dimensional scaling (NMDS) from the function metaMDS in vegan. NMDS is an ordination technique that represents highly dimensional data by maximizing the correlation of ranked-distances between the original highly dimensional data and a two dimensional representation (Faith et al. 1987, Minchin 1987). A stress score is calculated as a measure of how accurately the two dimensional ordination represents the distances in the original data; stress scores $<0.2$ are generally considered acceptable (Clarke 1993). Communities grouped closely together in the ordination space are interpreted as being more similar than those placed farther away.

\section{Results}

\section{Biodiversity across grazing regimes}

All three of our plant richness metrics, species richness (mean \pm SD (range): $20.75 \pm 7.26(6.22-41.11$ ) species), the Shannon-Wiener diversity index i.e. H' $(1.79 \pm 0.56(0.33-2.88))$, and the index of evenness, i.e. $\mathrm{E}_{\mathrm{var}}(0.41 \pm 0.11(0.16-0.98))$, varied markedly among plots. However, analyses using linear mixed effect models revealed that grazing intensity does not explain a significant amount of this variation. Species richness varied with year $\left(\mathrm{F}_{3,128}=5.58, \mathrm{P}=0.001\right)$, as the average species richness/plot was greater in 2004 (lsmean \pm SE: $24.7 \pm 1.4$ species) than $2005(20.4 \pm 1.4$ species; $\mathrm{P}=0.04), 2006(19.2 \pm 1.4$ species; $\mathrm{P}=$ $0.005)$, and $2007(19.2 \pm 1.4$ species; $\mathrm{P}=0.002)$, but was independent of wet/dry $\left(\mathrm{F}_{1,128}=0.001, \mathrm{P}=0.97\right)$, grazing $\left(\mathrm{F}_{2,128}=0.35, \mathrm{P}=0.70\right)$, and the grazing:year interaction $\left(\mathrm{F}_{6,122}=0.13, \mathrm{P}=0.99\right)$. Similarly, $\mathrm{H}$ ' varied with year $\left(\mathrm{F}_{3,128}=13.34, \mathrm{P}<0.0001\right)$ as plots from 2004 (lsmean $\pm \mathrm{SE}: 2.13 \pm 0.09$ ) were more diverse than plots from $2006(1.59 \pm 0.09 ; \mathrm{P}<0.0001)$ and $2007(1.49 \pm 0.09 ; \mathrm{P}<0.0001)$, and plots from $2005(1.93 \pm 0.09)$ were more diverse than plots from $2006(\mathrm{P}=0.02)$ and $2007(\mathrm{P}=0.001)$. H' was also independent of grazing $\left(\mathrm{F}_{2,128}=2.00, \mathrm{P}=0.13\right)$ and the grazing:year interaction $\left(\mathrm{F}_{6,122}=0.32, \mathrm{P}=0.92\right)$, but, contrary to $\mathrm{SR}$, did vary with wet/dry $\left(\mathrm{F}_{1,128}=5.51, \mathrm{P}=0.02\right.$; lsmean $\pm \mathrm{SE}$ dry plots: $1.89 \pm 0.08$, wet plots: $1.68 \pm 0.08)$. Finally, $\mathrm{E}_{\mathrm{var}}$ did not vary with wet/dry $\left(\mathrm{F}_{1,128}=0.68, \mathrm{P}=0.41\right)$, year $\left(\mathrm{F}_{3,128}=\right.$ $0.35, \mathrm{P}=0.78)$, grazing $\left(\mathrm{F}_{2,128}=0.91, \mathrm{P}=0.40\right)$, or their interaction $\left(\mathrm{F}_{6,122}=0.57, \mathrm{P}=0.76\right)$. 


\section{Community structure across grazing regimes}

Wet/dry, grazing intensity, and year were all able to explain a significant amount of the variation in overall vascular plant community structure in the PERMANOVA $(\mathrm{P}<=0.002$ for each; Table 2; Figure 2). Post-hoc analysis revealed that the effect of grazing intensity on community structure was significant between plots with light and pulse grazing (Bonferroni adjusted $\mathrm{p}=0.003$ ) and between plots with light and press grazing (Bonferroni adjusted $\mathrm{p}=0.003$ ), but not between plots with press and pulse grazing (Bonferroni adjusted $\mathrm{p}=0.27$; Figure $2 \mathrm{~b}$ ). The effect of year on community structure was only significant between plots in years 2004 and plots 2007 (Bonferroni adjusted $\mathrm{p}=0.006$; Figure 2c).

In addition to the variation in each of the above metrics of overall plant richness, there was also substantial variation among plots in the mean species richness of shrubs (mean $\pm \mathrm{SD}$ (range): $3.55 \pm 1.84$ (0.11 - 9.00) species), herbs (11.05 $\pm 5.22(1.56-22.56)$ species $)$, and graminoids $(6.15 \pm 2.63(1.44-12.56)$ species $)$. The number of shrub species was independent of year $\left(\mathrm{F}_{3,128}=1.87, \mathrm{P}=0.14\right)$ and the grazing:year interaction $\left(\mathrm{F}_{6,122}=0.11, \mathrm{P}=0.99\right)$, but varied with grazing intensity $\left(\mathrm{F}_{2,128}=30.27 \mathrm{P}<0.0001\right)$ and wet $/$ dry $\left(\mathrm{F}_{1,128}\right.$ $=44.63, \mathrm{P}<0.0001)$; lightly grazed plots had more shrub species than plots with pulse $(\mathrm{P}<0.0001)$ and press grazing $(\mathrm{P}<0.0001$; Figure $3 \mathrm{a})$, and dry plots (lsmean $\pm \mathrm{SE}: 4.23 \pm 0.33$ species) had more shrub species than wet plots $(2.77 \pm 0.33$ species $)$. The number of graminoid species varied with year $\left(\mathrm{F}_{3,128}=\right.$ $13.11 \mathrm{P}<0.0001$ ), as plots from 2004 (lsmean $\pm \mathrm{SE}: 7.84 \pm 0.54$ species) had more species of graminoids than plots from $2005(6.00 \pm 0.54$ species; $\mathrm{P}=0.0005), 2006(5.74 \pm 0.54$ species; $\mathrm{P}=0.0001)$ and $2007(5.08$ \pm 0.55 species; $\mathrm{P}<0.0001)$, but was independent of wet/dry $\left(\mathrm{F}_{1,128}=0.05, \mathrm{P}=0.82\right)$ and the grazing:year interaction $\left(\mathrm{F}_{6,122}=0.30, \mathrm{P}=0.93\right)$. Complementing the effect of grazing intensity on shrub species richness, the species richness of graminoids also varied with grazing intensity $\left(\mathrm{F}_{2,128}=23.24, \mathrm{P}<0.0001\right)$ as lightly grazed plots had fewer graminoid species compared to plots with pulse $(\mathrm{P}<0.0001)$ and press grazing $(\mathrm{P}$ $<0.0001$; Figure 3b). In contrast, the species richness of herbs did not vary with wet/dry $\left(\mathrm{F}_{1,128}=2.70\right.$, $\mathrm{P}=0.10)$, year $\left(\mathrm{F}_{3,128}=2.30, \mathrm{P}=0.08\right)$, grazing $\left(\mathrm{F}_{2,128}=0.15 \mathrm{P}=0.86\right.$; Figure $\left.3 \mathrm{c}\right)$ or the grazing:year interaction $\left(\mathrm{F}_{6,122}=0.07, \mathrm{P}=0.99\right)$.

Phylogenetic structure across grazing regimes

Phylogenetic dispersion (mean $\pm \mathrm{SD}$ (range): $0.44 \pm 0.08(0.24-0.60))$ varied with year $\left(\mathrm{F}_{3,128}=3.18 \mathrm{P}\right.$ $=0.03$ ) [plots from 2005 (lsmean \pm SE: $0.46 \pm 0.01$ ) were more phylogenetically dispersed than plots from $2004(0.41 \pm 0.01)]$, but was independent of wet/dry $\left(\mathrm{F}_{1,128}=0.32, \mathrm{P}=0.57\right)$, grazing intensity $\left(\mathrm{F}_{2,128}=\right.$ $0.16, \mathrm{P}=0.85$; Figure 4a) and the grazing:year interaction $\left(\mathrm{F}_{6,122}=1.52, \mathrm{P}=0.18\right)$. Controlling for the proportion of species that are graminoids in each plot, the effect of year remained $\left(\mathrm{F}_{2,127}=3.06, \mathrm{P}=0.03\right)$. In contrast to the patterns of unweighted phylogenetic dispersion, the abundance-weighted measure (mean \pm $\mathrm{SD}$ (range): $0.41 \pm 0.26(0.03-0.95))$ varied with grazing intensity $\left(\mathrm{F}_{2,128}=5.72, \mathrm{P}=0.004\right)$, and wet/dry $\left(\mathrm{F}_{1,128}=14.25, \mathrm{P}=0.0002\right)$ [wet plots (lsmean $\left.\pm \mathrm{SE}: 0.33 \pm 0.04\right)$ were more clumped than dry plots (lsmean \pm SE: $0.48 \pm 0.04)]$, though not with year $\left(\mathrm{F}_{3,128}=0.91, \mathrm{P}=0.44\right)$ or the grazing:year interaction $\left(\mathrm{F}_{6,122}\right.$ $=0.32, \mathrm{P}=0.93)$. After controlling for the proportion of the relative abundance of graminoids, the effect of grazing intensity on abundance-weighted phylogenetic dispersion remained $\left(\mathrm{F}_{2,127}=9.92, \mathrm{P}<0.0001\right)$. Importantly, plots with pulse grazing were more phylogenetically dispersed than plots with both light $(\mathrm{P}=$ $0.007)$ and press grazing $(\mathrm{P}=0.02)$, while there was no difference in dispersion between plots with light and press grazing $(\mathrm{P}=0.91$; Figure $4 \mathrm{~b})$.

\section{Discussion}

We report for the first time that frequency of grazing has effects on the phylogenetic community structure that are not captured by standard diversity indexes. Plant communities grazed every other year (i.e. pulse grazing), but not communities grazed every year (i.e. press grazing) were more phylogenetically dispersed than lightly grazed communities, while there was no effect of grazing on species richness, the Shannon-Wiener index $\left(\mathrm{H}^{\prime}\right)$ and community evenness $\left(\mathrm{E}_{\mathrm{var}}\right)$. This does not support our predictions that grazing would act as a biotic filter, resulting in communities that are more phylogenetically clustered, but rather suggests that pulses of grazing release biological control and allow more phylogenetically diverse communities. 
We observed no effect of grazing on species richness, the Shannon-Wiener index (H') and community evenness $\left(\mathrm{E}_{\mathrm{var}}\right)$. Since the productivity of our study site is intermediate, these results are in agreement with previous studies, which show that excluding reindeer decreases species richness in sites with low productivity, but increases species richness in productive sites (Proulx and Mazumder 1998, Bernes et al. 2015, Sundqvist et al. 2019). A neutral effect of reindeer grazing on species diversity is expected for sites that have intermediate productivity in this region (Sundqvist et al. 2019).

While we do not observe a change in the overall richness and evenness of vascular plants across grazing regimes, we do detect an effect of grazing on the species composition of communities. Plots with pulse and press grazing both differed in community structure from lightly grazed plots (Figure 2a) as there was a transition from shrubs to graminoids that occurred with grazing (Figure 3). These results are fully consistent with previous studies in Fennoscandia that report the replacement of dwarf shrubs by graminoids in grazed areas (Olofsson et al. 2001). Similar effects of grazing on vegetation composition have also been observed in other systems (McKendrick et al. 1980, Clarke et al. 1995, Rooney 2009, Begley-Miller et al. 2014, Ferreira et al. 2020). For example, grazing by sheep in Great Britain has resulted in the replacement of heather moorlands with graminoids (Clarke et al. 1995), and grazing by mammalian herbivores in northern Alaska also resulted in the replacement of tundra heaths by graminoids (McKendrick et al. 1980). Potential reasons for this shift in vegetation composition include increased soil nutrient concentrations that favour graminoids (McKendrick et al. 1980) and an increased ability of graminoids to outcompete shrubs and ferns in heavily grazed environments due to their short stature, high shoot densities, and capacity for compensatory growth (Coughenour 1985). This combination of traits allows graminoids to be the first plants to colonize following disturbances (Chapin and Shaver 1981). Interestingly, the shift from shrubs to graminoids was also observed in plots with several years of pulse grazing (Figure 2a; Figure 3). This may be explained by the decades of chronic grazing these plots were exposed to before the temporary fences were established.

Our novel analysis of the effect of reindeer grazing on the phylogenetic structure of vascular plant communities revealed that communities with pulse, but not press grazing seem more phylogenetically dispersed than lightly grazed communities (Figure 4). This is in contrast to our prediction that, assuming anti-herbivore traits are evolutionarily conserved (Loiola et al. 2012, Yessoufou et al. 2013, but see Kursar et al. 2009) and reindeer are generalist herbivores (Baskin and Danell 2003), reindeer grazing would result in communities that are more phylogenetically clustered compared to lightly-grazed communities (Cavender-Bares et al. 2009). Other studies examining the effect of grazing on phylogenetic structure have found conflicting results. Grazing by white-tailed deer (Odocoileus virginianus) resulted in phylogenetic clumping (Begley-Miller et al. 2014), but grazing by large herbivores in the African savanna resulted in changes in phylogenetic community structure dependent on the initial community structure: communities that were initially clumped became more dispersed while communities that were initially dispersed became more clumped (Yessoufou et al. 2013). In contrast, grazing by livestock had no effect on the phylogenetic dispersion of plant communities in Chile (Salgado-Luarte et al. 2019). One potential explanation for our result is that anti-herbivore defense traits are actually evolutionarily convergent in our study region, a situation where grazing by a generalist herbivore would result in phylogenetic clumping (Cavender-Bares et al. 2009). However, it should be noted that this predicted effect of grazing on the phylogenetic structure of plant communities by Cavender-Bares et al. (2009) is based only on the direct effects of herbivory (i.e. the physical removal of species) and does not account for the indirect effects on e.g. productivity, nutrient availability, trampling disturbance and competitive interactions between species. For example, if herbivory increases soil nutrient availability and decreases competition between plant species, this might lead to phylogenetic clumping, given that both competition between distantly related taxa (Mayfield and Levine 2010) and limited nutrient availability (Hurteau et al. 2016) may drive phylogenetic clumping. In this case, the indirect effects of grazing by herbivores on phylogenetic structure may act in the opposite direction of direct effects of grazing, and the resulting phylogenetic structure may depend on the relative strength of the direct and indirect effects. Given that we found that pulse, but not press, grazing results in increased phylogenetic dispersion, it is possible that in our study system, the indirect effects of reindeer grazing are more important than the direct effects in driving community assembly for plant communities that are exposed to acute periods of grazing after 
decades of chronic grazing.

The results of this study may be relevant to management decisions involving reindeer in Fennoscandia. While we do not observe any richness effects of reindeer grazing, we do observe a significant effect of grazing on vegetation composition and phylogenetic structure. More specifically, several years of pulse grazing (following over forty years of chronic grazing) increased the phylogenetic dispersion of vascular plant communities compared to plots with almost no grazing and plots with continued press grazing. Changes to the phylogenetic structure of communities may have important consequences for community function if phylogenetic diversity captures genetic and functional diversity related to ecosystem productivity (see, e.g. Cadotte et al. 2009, Flynn et al. 2011). Given the numerous studies that have analyzed the impact of reindeer herbivory on vegetation composition, there is a potential to re-analyze existing datasets using the framework of phylogenetic community ecology as done here. Additionally, future studies considering variation in productivity and grazing intensity will reveal if general relationship between grazing and phylogenetic diversity exist in the same way they do for common diversity measures, or whether the responses depend on other factors such as the evolutionary history of plants and herbivores. Direct measurement of ecosystem function in such experimental communities are also needed to help understand the mechanisms driving plant community assembly in support of future management decisions.

\section{Declarations}

Ackowledgements: We thank Lauri Oksanen for knowledge of the study area and design and Oleg Dmytrenko, Jonas Gustafsson, Pirjo Isotupa, Marisano James, Maciek Koperwas, Nicolai Krichevsky, Anne Muola, Karin Nilsson, Antti Oksanen, Lotta Ström and Gunnar Öhlund for help in the field. We also thank James Bodnarchuk and Sara Durkin for help with the phylogenetic analyses.

Funding: Funding for this study was provided by the Swedish Research Council (MJM grant number 6372013-274) and NSERC Canada (AOM).

Data accessibility: Data will be submitted to Dryad upon acceptance.

Competing interests: The authors declare no competing interests.

\section{Author contributions:}

KG: Formal analysis, visualization, writing-original draft

JO: Data curation, writing-review + editing

AOM: Supervision, writing-review + editing

MJM: Data curation, conceptualization, funding acquisition, supervision, writing-review + editing

\section{References}

Augustine, D. J. and McNaughton, S. J. 1998. Ungulate effects on the functional species composition of plant communities: herbivore selectivity and plant tolerance. - J. Wildl. Manage. 62: 1165-1183.

Austrheim, G. and Eriksson, O. 2001. Plant species diversity and grazing in the Scandinavian mountains patterns and processes at different spatial scales. - Ecography 24: 683-695.

Bakker, C. et al. 2003. Does resource availability, resource heterogeneity or species turnover mediate changes in plant species richness in grazed grasslands? - Oecologia 137: 385-391.

Baskin, L. and Danell, K. 2003. Ecology of Ungulates: A Handbook of Species in Eastern Europe and Northern and Central Asia. - Springer-Verlag.

Begley-Miller, D. R. et al. 2014. White-tailed deer are a biotic filter during community assembly, reducing species and phylogenetic diversity. - AoB Plants 6: plu030. 
Bell, C. D. et al. 2010. The age and diversification of the angiosperms re-revisited. - Am. J. Bot. 97: 12961303.

Bernes, C. et al. 2015. What are the impacts of reindeer/caribou (Rangifer tarandus L.) on arctic and alpine vegetation? A systematic review. - Environ. Evid. 4: 1-26.

Cadotte, M. W. et al. 2009. Using phylogenetic, functional and trait diversity to understand patterns of plant community productivity. - PLoS One 4: 1-9.

Cavender-Bares, J. et al. 2009. The merging of community ecology and phylogenetic biology. - Ecol. Lett. 12: $693-715$.

Chapin, F. S. and Shaver, G. R. 1981. Changes in soil properties and vegetation following disturbance of alaskan arctic tundra. - J. Appl. Ecol. 18: 605-617.

Clarke, K. R. 1993. Non-parametric multivariate analyses of changes in community structure. - Aust. J. Ecol. 18: $117-143$.

Clarke, J. L. et al. 1995. The influence of vegetation pattern on the grazing of heather moorland by red deer and sheep II. - J. Appl. Ecol. 32: 177-186.

Connell, J. H. 1978. Diversity in tropical rain forests and coral reefs. - Science 199: 1302-1310.

Coughenour, M. B. 1985. Graminoid responses to grazing by large herbivores: adaptations, exaptations, and interacting processes. - Ann. Missouri Bot. Gard. 72: 852-863.

Faith, D. P. 1992. Conservation evaluation and phylogenetic diversity. - Biol. Conserv. 61: 1-10.

Faith, D. P. et al. 1987. Compsitional dissimilarity as a robust measure of ecogical distance. - Vegetatio 69: $57-68$.

Ferreira, P. M. A. et al. 2020. Long-term ecological research in southern Brazil grasslands: Effects of grazing exclusion and deferred grazing on plant and arthropod communities. - PLoS One 15: 1-23.

Flynn, D. F. B. et al. 2011. Functional and phylogenetic diversity as predictors of biodiversity-ecosystemfunction relationships. - Ecology 92: 1573-1581.

Gasteiger, E. et al. 2003. ExPASy: The proteomics server for in-depth protein knowledge and analysis. Nucleic Acids Res. 31: 3784-3788.

Gotelli, N. J. 2000. Null model analysis of species co-occurrence patterns. - Ecology 81: 2606-2621.

Grime, J. P. 1973. Control of species density in herbaceous vegetation. - J. Environ. Manage. 1: 151-161.

Huelsenbeck, J. P. and Ronquist, F. 2001. MRBAYES: Bayesian inference of phylogenetic trees. - Bioinformatics 17: 754-755.

Hurteau, L. A. et al. 2016. Salmon nutrients are associated with the phylogenetic dispersion of riparian flowering-plant assemblages. - Ecology 97: 450-460.

Huston, M. 1979. A general hypothesis of species diversity. - Am. Nat. 113: 81-101.

Kembel, S. W. et al. 2010. Picante: R tools for integrating phylogenies and ecology. - Bioinformatics 26 : 1463-1464.

Kumar, S. et al. 2016. MEGA7: molecular evolutionary genetics analysis version 7.0 for bigger datasets. Mol. Biol. Evol. 33: 1870-1874.

Kursar, T. A. et al. 2009. The evolution of antiherbivore defenses and their contribution to species coexistence in the tropical tree genusInga . - Proc. Natl. Acad. Sci. 106: 18073-18078. 
Lipnerová, I. et al. 2013. Evolution of genome size in Carex(Cyperaceae) in relation to chromosome number and genomic base composition. - Ann. Bot. 111: 79-94.

Liu, J. et al. 2018. Biodiversity explains maximum variation in productivity under experimental warming, nitrogen addition, and grazing in mountain grasslands. - Ecol. Evol. 8: 10094-10112.

Loiola, P. P. et al. 2012. Underdispersion of anti-herbivore defence traits and phylogenetic structure of cerrado tree species at fine spatial scale. - J. Veg. Sci. 23: 1095-1104.

Lubchenco, J. 1978. Plant species diversity in a marine intertidal community: Importance of herbivore food preference and algal competitive abilities. - Am. Nat. 112: 23-29.

Mayfield, M. M. and Levine, J. M. 2010. Opposing effects of competitive exclusion on the phylogenetic structure of communities. - Ecol. Lett. 13: 1085-1093.

Mazumder, A. et al. 1988. Effects of fertilization and planktivorous fish (yellow perch) predation on size distribution of particulate phosphorus and assimilated phosphate: Large enclosure experiments. - Limnol. Oceanogr. 33: 421-430.

McKendrick, J. D. et al. 1980. Some effects of mammalian herbivores and fertilization on tundra soils and vegetation. - Arct. Alp. Res. 12: 565-578.

McNaughton, S. J. et al. 1988. Large mammals and process dynamics in African ecosystems: Herbivorous mammals affect primary productivity and regulate recycling balances. - Bioscience 38: 794-800.

Minchin, P. R. 1987. An evaluation of the relative robustness of techniques for ecological ordination. Vegetatio 69: 89-107.

Oksanen, L. and Virtanen, R. 1995. Topographic, altitudinal and regional patterns in continental and suboceanic heath vegetation of northern Fennoscandia. - Acta Bot. Fenn. 153: 1-80.

Oksanen, J. et al. 2019. vegan: Community Ecology Package. R package version 2.5-6.

Olff, H. and Ritchie, M. E. M. 1998. Effects of herbivores on grassland plant diversity. - Trends Ecol. Evol. 13: 261-265.

Olofsson, J. and Oksanen, L. 2005. Effects of reindeer density on vascular plant diversity on North Scandinavian mountains. - Rangifer 25: 5-18.

Olofsson, J. et al. 2001. Effects of summer grazing by reindeer on composition of vegetation, productivity and nitrogen cycling. - Ecography 24: 13-24.

Olofsson, J. et al. 2004. Importance of large and small mammalian herbivores for the plant community structure in the forest tundra ecotone. - Oikos 106: 324-334.

Proulx, M. and Mazumder, A. 1998. Reversal of grazing impact on plant species richness in nutrient-poor vs. nutrient-rich ecosystems. - Ecology 79: 2581-2592.

R Core Team 2019. R: A language and environment for statistical computing.

Rooney, T. P. 2009. High white-tailed deer densities benefit graminoids and contribute to biotic homogenization of forest ground-layer vegetation. - Plant Ecol. 202: 103-111.

Rosenzweig, M. L. 1971. Paradox of enrichment: destabilization of exploitation ecosystems in ecological time. - Science 171: 385-387.

Salgado-Luarte, C. et al. 2019. Goat grazing reduces diversity and leads to functional, taxonomic, and phylogenetic homogenization in an arid shrubland. - L. Degrad. Dev. 30: 178-189.

Scheen, A. C. et al. 2004. Northern hemisphere biogeography of Cerastium (Caryophyllaceae): Insights from phylogenetic analysis of noncoding plastid nucleotide sequences. - Am. J. Bot. 91: 943-952. 
Shannon, C. and Weaver, W. 1949. The Mathematical Theory of Communication. - The University of Illinois Press.

Smith, B. and Wilson, J. B. 1996. A consumer's guide to evenness indices. - Oikos 76: 70-82.

Stenberg, L. and Mossberg, B. 2003. Den nya nordiska floran. - Wahlstrom \& Widstrand.

Sundqvist, M. K. et al. 2019. Experimental evidence of the long-term effects of reindeer on Arctic vegetation greenness and species richness at a larger landscape scale. - J. Ecol. 107: 2724-2736.

Suominen, O. and Olofsson, J. 2000. Impacts of semi-domesticated reindeer on structure of tundra and forest communities in Fennoscandia: a review. - Ann. Zool. Fennici 37: 233-249.

Tilman, D. et al. 1997. Plant diversity and ecosystem productivity: Theoretical considerations. - Proc. Natl. Acad. Sci. U. S. A. 94: 1857-1861.

Uboni, A. et al. 2016. Long-term trends and role of climate in the population dynamics of eurasian reindeer.

- PLoS One 11: 1-20.

Vamosi, J. C. et al. 2014. Pollinators visit related plant species across 29 plant-pollinator networks. - Ecol. Evol. 4: 2303-2315.

Webb, C. O. et al. 2002. Phylogenies and community ecology. - Annu. Rev. Ecol. Syst. 33: 475-505.

Yessoufou, K. et al. 2013. Large herbivores favour species diversity but have mixed impacts on phylogenetic community structure in an African savanna ecosystem. - J. Ecol. 101: 614-625.

\begin{tabular}{lllll}
\hline Node & Minimum & Mean & SD & Fixed \\
\hline Root & 407.60 & 430.82 & 10.20 & NA \\
Monilophytes & 346.70 & 364.93 & 8.01 & NA \\
Euphyllophytes & NA & NA & NA & 380.00 \\
Angiosperms & 113.00 & 133.27 & 8.90 & NA \\
Ranunculales & 112.00 & 132.81 & 9.14 & NA \\
Saxifragales & 89.30 & 101.73 & 5.46 & NA \\
Caryophyllales & 83.50 & 99.11 & 6.86 & NA \\
\hline
\end{tabular}

Table 1. Node constraints (in million years) from Bell et al. (2010) input to MrBayes for dating the regional vascular plant phylogeny from Fennoscandia.

\begin{tabular}{llllll}
\hline Variable & df & SS & MS & Pseudo-F & P \\
\hline wet/dry & 1 & 3.15 & 3.15 & 9.66 & 0.001 \\
grazing & 2 & 3.64 & 1.82 & 5.58 & 0.001 \\
year & 3 & 1.67 & 0.56 & 1.71 & 0.002 \\
grazing*year & 6 & 0.78 & 0.13 & 0.40 & 1 \\
residual & 127 & 41.45 & 0.33 & & \\
total & 139 & 50.69 & & & \\
\hline
\end{tabular}

Table 2. Results from the permutational multivariate analysis (PERMANOVA) of the Bray-Curtis dissimilarities for vascular plant community structure in relation to wet/dry, grazing, year, and the grazing*year interaction, $\mathrm{df}=$ degrees of freedom; $\mathrm{SS}=$ sum of squares; $\mathrm{MS}=$ mean sum of squares; Pseudo-F $=\mathrm{F}$ value from permutations. P-values are based on 1000 permutations.

Figure captions 
Figure 1. Study design. a) Design of one temporary fence. The temporary fence allows the most heavily grazed area of the permanent fence to only be grazed every other year. b) Plot setup at five temporary fences. Each temporary fence has one pair of triplicate plots, except for fence 4, which has two pairs of triplicates. Each triplicate has one plot that was grazed every year (i.e. press grazing), one plot that was grazed every $2^{\text {nd }}$ year (i.e. pulse razing) and one plot that was lightly grazed. One triplicate in each pair was placed in a drier area (D), while the other triplicate was placed in a wetter area $(\mathrm{W})$.

Figure 2. Plant community structure is altered by pulse and press reindeer grazing and in wet vs. dry plots. Non-metric multidimensional scaling (NMDS) of a Bray-Curtis distance matrix describing vascular plant communities in Fennoscandia. NMDS is an ordination technique that creates a 2-dimensional representation of highly dimensional data. Each point symbolizes a plant community from an individual plot $(\mathrm{n}=140)$ and colours display the characteristics of each plot: a) plots with light, pulse, or press reindeer grazing, b) plots in wet or dry areas and c) the year the plot was sampled in. The stress value, a measure of the disagreement between the rank order in the data set and the 2-dimensional NMDS, is 0.18.

Figure 3. Shrub species are replaced by grass species in plots with pulse and press grazing. The effect of reindeer grazing on a) shrubs species richness, b) herbs species richness, and c) graminoid species richness in Fennoscandia. Different numbers indicate statistical significance between groups at the $\mathrm{P}<0.05$ level, tested using an ANOVA in a linear mixed effects model.

Figure 4. The phylogenetic dispersion of plant communities increases in plots with pulse but not press grazing. The effect of reindeer grazing on a) phylogenetic dispersion (calculated from species presence/absence data) and b) abundance-weighted phylogenetic dispersion (calculated from relative species abundance data) of vascular plant communities in Fennoscandia. Values of phylogenetic dispersion close to 0 represent phylogenetically clumped communities, while values close to 1 represent phylogenetically dispersed communities. Different numbers indicate statistical significance between groups at the $\mathrm{P}<0.05$ level, tested using an ANOVA in a linear mixed effects model, controlling for a) the proportion of species that are graminoids and $b$ ) the proportion of the relative abundance that are graminoids. 
(a)

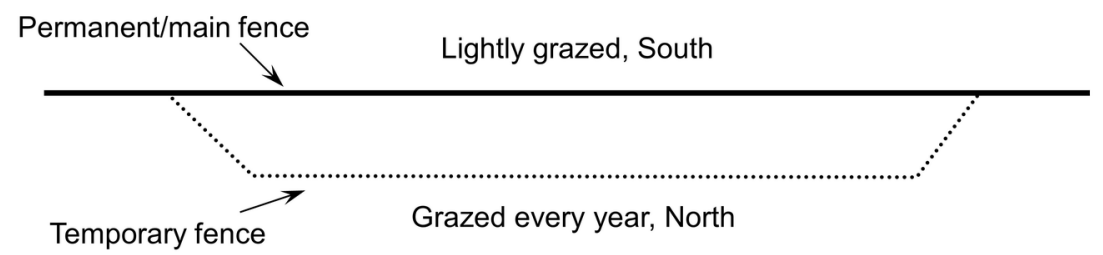

(b)

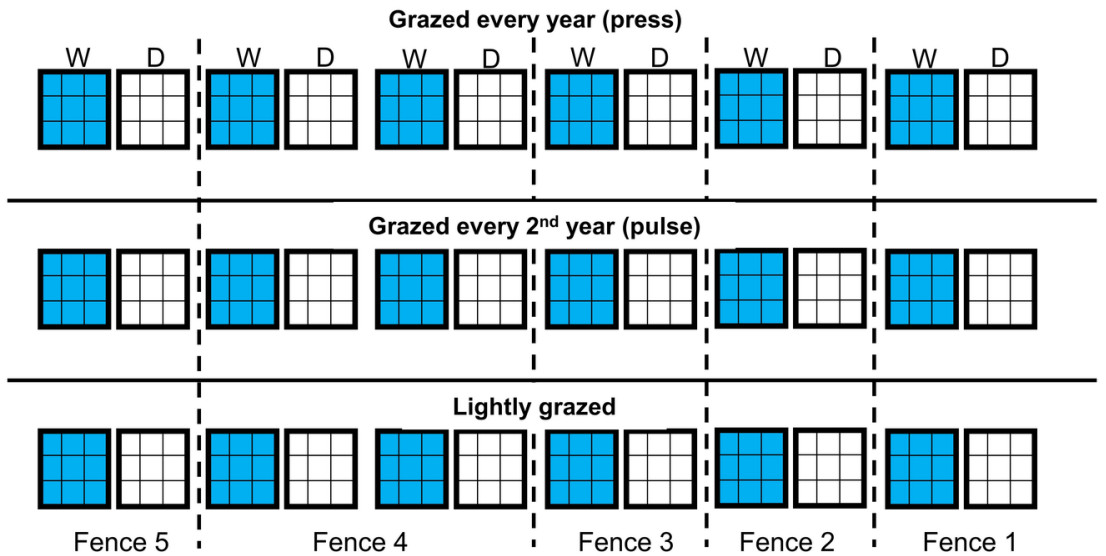



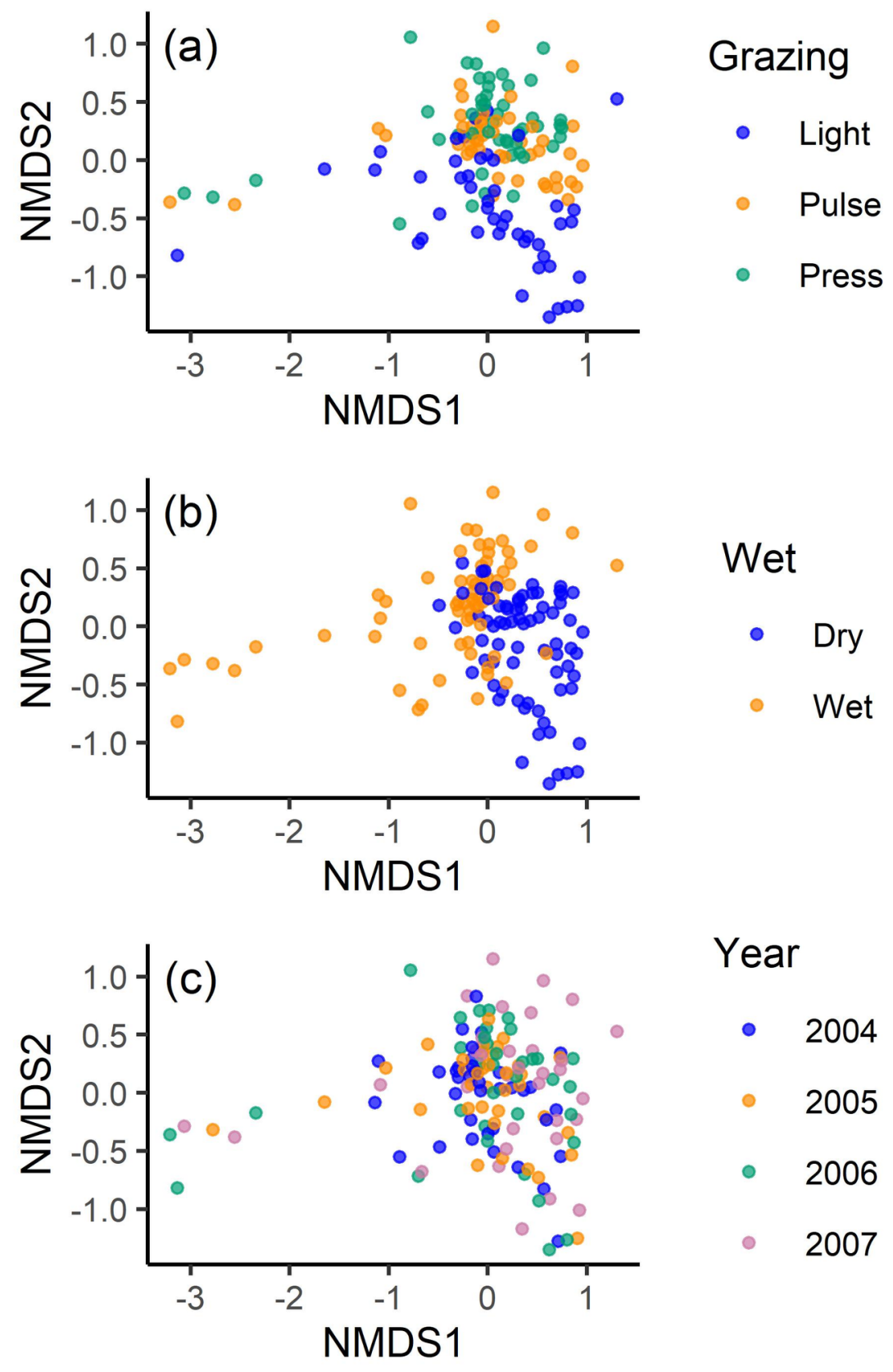

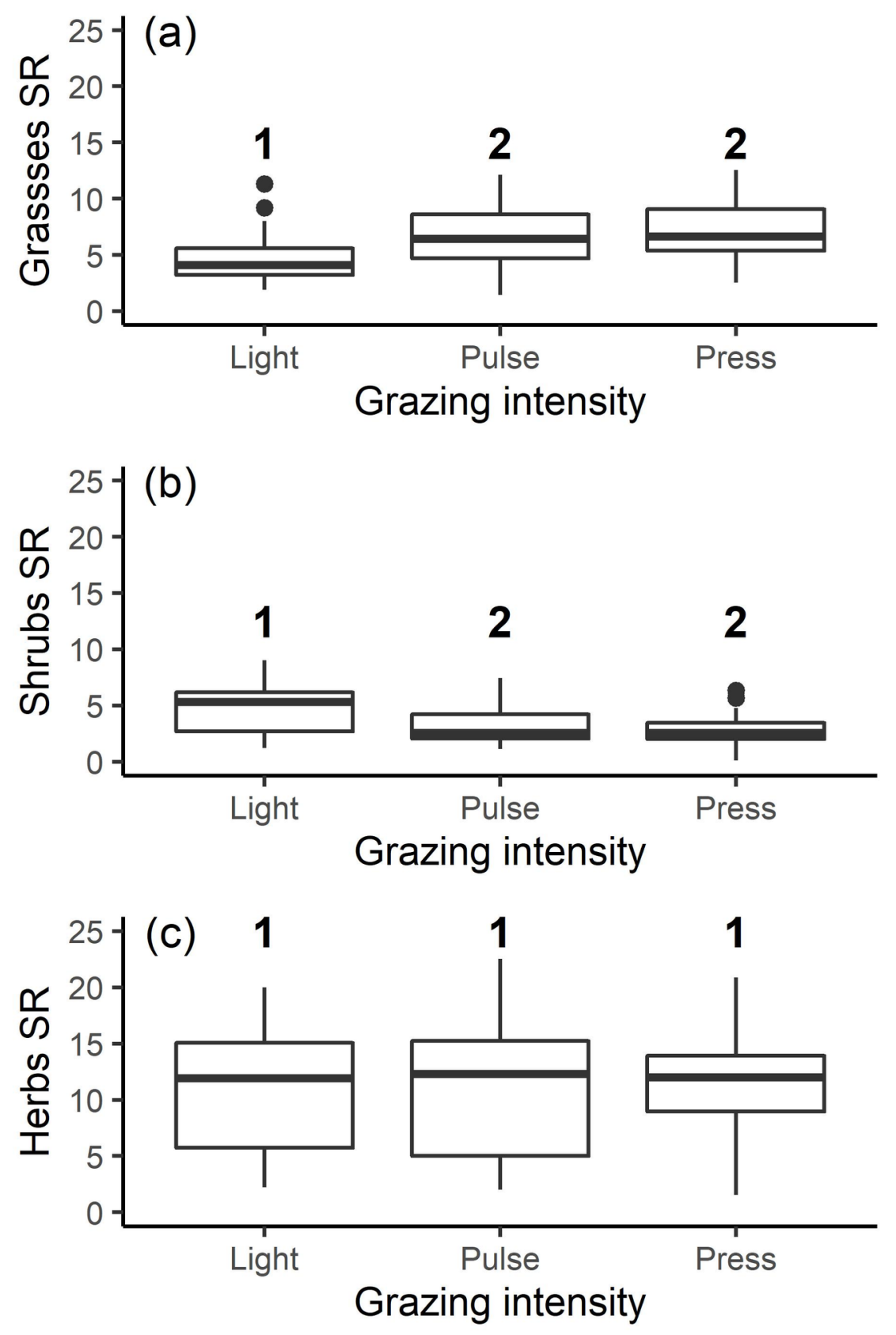

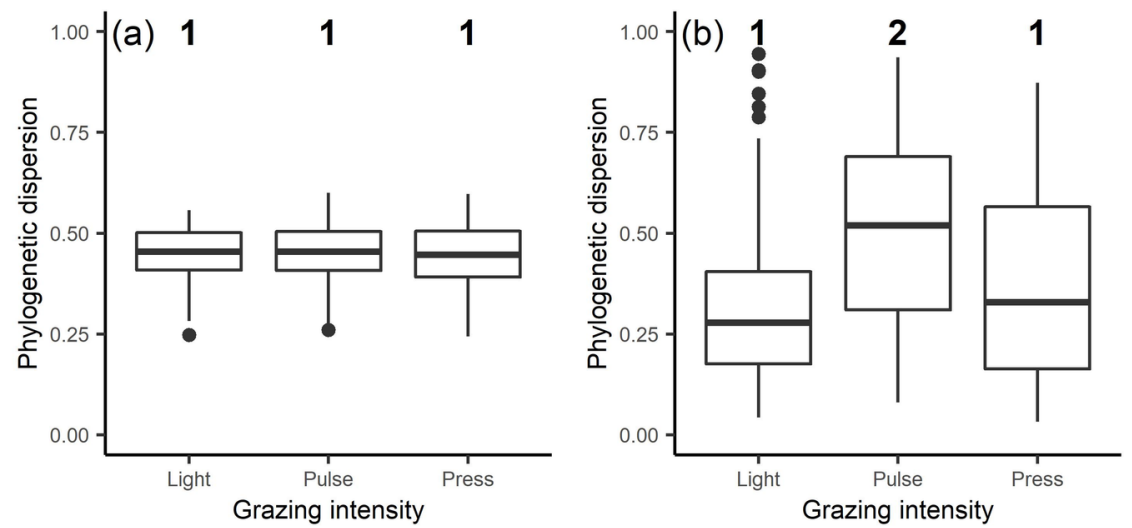